\title{
Primary Amebic Meningoencephalitis Arizona, Florida, and Texas, 2007
}

\author{
Source: Morbidity and Mortality Weekly Report (MMWR), Centers for Disease Control
} (cdc.gov), May 30, 2008/57(21); 573-577

Primary amebic meningoencephalitis (PAM) is a rare but nearly always fatal disease caused by infection with Naegleria fowleri, a thermophilic, free-living ameba found in freshwater environments $(1,2)$. Infection results from water containing $N$. fowleri entering the nose, followed by migration of the amebae to the brain via the olfactory nerve. In 2007, six cases of PAM in the United States were reported to CDC; all six patients died. This report summarizes the investigations of the cases, which occurred in three southern tier states (Arizona, Florida, and Texas) during June--September and presents preliminary results from a review of PAM cases during 1937--2007. Because deaths from PAM often prompt heightened concern about the disease among the public, an updated and consistent approach to $N$. fowleri risk reduction messages, diagnosis and treatment, case reporting, and environmental sampling is needed.

\section{Case Reports}

Arizona. An adolescent boy aged 14 years was hospitalized September 16, 2007, with possible meningitis. His symptoms had begun September 14 with severe headache, stiff neck, and fever. $N$. fowleri was detected in cerebrospinal fluid (CSF). The youth died from PAM on September 17. He had been swimming in a northeastern Arizona lake on September 8 and was observed diving and splashing in shallow water. The water temperature on September 8 was $86.3^{\circ} \mathrm{F}$ $\left(30.2^{\circ} \mathrm{C}\right)$ and the air temperature was $108.0^{\circ} \mathrm{F}\left(42.2^{\circ} \mathrm{C}\right)$.

Florida. On June 8, 2007, an adolescent boy aged 14 years was admitted to an emergency department (ED). His symptoms had begun June 6 with a sensation of ear pressure and progressed to severe headache and occasional vomiting the next day. On the day of admission, the youth was unable to walk and was found apneic and pulseless by paramedics. He died shortly after arriving at the ED. A diagnosis of PAM was confirmed by examination of postmortem brain tissue on September 7. The youth had access to multiple drainage ditches and canals and to an apartment swimming pool during the 2 weeks before onset of symptoms; no location was conclusively identified as the source of exposure.

On August 6, 2007, a boy aged 11 years was admitted to a hospital with possible bacterial meningitis, headache, fever, nausea, vomiting, and confusion. His symptoms had begun 4 days earlier on August 2, 2007, with headache and a faint rash. Motile amebae, later identified as $N$. fowleri, were found in CSF samples collected August 7. The same day, the patient was treated with amphotericin B, epinephrine, mannitol, fluconazole, ceftriaxone, azithromycin, and rifampin; however, the boy died August 8. The probable source of exposure was swimming and wakeboarding at a local lake on July 28 . On that date, the air temperature was $91.0^{\circ} \mathrm{F}\left(32.8^{\circ} \mathrm{C}\right)$; water temperature was unknown. 
On September 2, 2007, a boy aged 10 years was evaluated in a local ED for headache, body aches, high fever, nausea, vomiting, and fainting. His symptoms had begun on August 31 with headache and lethargy. After admission to a hospital, his symptoms rapidly progressed to a fever of $104.0^{\circ} \mathrm{F}\left(40.0^{\circ} \mathrm{C}\right)$, confusion, and abdominal pain. Motile amebae, later identified as $N$. fowleri, were found in CSF on September 3--4. Amphotericin B, rifampin, azithromycin, and fluconazole were administered; however, the boy died September 4. The patient's exposure history included swimming and wakeboarding at a privately owned water sports facility on August 19 and August 26. On the latter date, the water temperature of the lake was $89.0^{\circ} \mathrm{F}$ $\left(31.7^{\circ} \mathrm{C}\right)$, and the air temperature was $94.0^{\circ} \mathrm{F}\left(34.4^{\circ} \mathrm{C}\right)$.

Texas. In August 2007, a boy aged 12 years was admitted to a hospital with a 6-day history of fever. His mother reported her son had become disoriented and lethargic. The boy had been attending a summer camp in Central Texas in the weeks preceding his illness and had participated in recreational water activities in a lake cove. During the week before hospitalization, he visited the camp nurse three times, reporting he was "not feeling well." After admission to the hospital, analysis of the boy's CSF indicated opaque appearance, bloody color, a white blood cell count of 1,750 cells $/ \mathrm{mm}^{3}$ (normal: $0--5$ cells $/ \mathrm{mm}^{3}$ ), red blood cell count of 30,750 cells $/ \mathrm{mm}^{3}$ (normal: 0 cells $/ \mathrm{mm}^{3}$ ), a glucose level of $92 \mathrm{mg} / \mathrm{dL}$ (normal: $40--70 \mathrm{mg} / \mathrm{dL}$ ), and a protein level of $88 \mathrm{mg} / \mathrm{dL}$ (normal: $15--45 \mathrm{mg} / \mathrm{dL}$ ). The admitting differential diagnosis included meningitis (bacterial, viral, or amebic), pneumonia, and bacteremia. Amebae, later identified as N. fowleri, were observed in CSF. Despite treatment with amphotericin B, rifampin, and azithromycin, the boy died 5 days after admission. Average water temperature of the lake during August 2007 was $84.4^{\circ} \mathrm{F}\left(29.1^{\circ} \mathrm{C}\right)$.

On August 31, 2007, a man aged 22 years was admitted to a hospital with symptoms of photosensitivity, altered mental status, and a severe headache that had begun suddenly 2 days before. The headache was frontal and described as a constant pressure sensation. A computer tomography scan of the head without contrast was interpreted as normal. The admission diagnosis was viral meningitis. Despite intensive treatment, the patient died September 4. N. fowleri was detected in postmortem brain specimens. According to acquaintances, the man had sustained a ruptured eardrum after a fall while wakeboarding in the same lake as the other Texas decedent on August 24, 7 days before admission to the hospital.

\section{Case Review, 1937--2007}

In response to the six PAM cases reported in 2007, CDC and the Council of State and Territorial Epidemiologists (CSTE) formed the Naegleria Workgroup* to review future actions related to $N$. fowleri and to determine whether the six cases represented an increase in the annual number of cases. The workgroup used multiple resources to conduct a review of all PAM cases reported in the United States during 1937--2007: 1) the Waterborne Disease and Outbreak Surveillance System, ${ }^{\dagger}$ which has tracked PAM cases since 1989; 2) the compressed mortality file of the National Vital Statistics System, searching on International Classification of Diseases, Ninth Revision (ICD-9) code 136.2 (specific infections by free-living amebae) and ICD-10 code B60.2 (naegleriasis) for the period 1979--2007; 3) medical literature review of reported PAM cases, including those identified by retrospective examination of autopsy records; 4) searches of media reports since 1990; and 5) CDC laboratory test results. Results were verified with public health 
officials from the state of diagnosis, and methods of diagnoses were reviewed by the CDC parasitic disease laboratory. Cases were included if laboratory-confirmed detection of $N$. fowleri organisms or nucleic acid was reported in CSF, biopsy, or tissue specimens.

Analyses of the data are still being conducted. Preliminary results indicate that a total of 121 cases (range: 0--8 cases per year) occurred in the United States during 1937--2007 (See figure, below). The six cases of PAM reported in 2007 were among the six highest annual totals of cases reported during the study period; the other five highest totals were 1980 (eight cases), 2002 (seven cases), and 1978, 1986, and 1995 (six cases each). During 1937--2007, median age of the patients was 12 years (range: 8 months--66 years). Among the 119 cases for which sex of the patient was known, males accounted for $93(78 \%)$ of the cases. Only one reported survivor met case criteria (3).

Exposure primarily occurred in untreated, warm, freshwater lakes or rivers in 15 southern tier states (Arizona, Arkansas, California, Florida, Georgia, Louisiana, Mississippi, Missouri, Nevada, New Mexico, North Carolina, Oklahoma, South Carolina, Texas, and Virginia); the state of exposure for four cases was unknown. Among the 112 cases for which month of exposure was known, 95 (85\%) occurred during July--September.

Reported by: S Matthews, MPH, Osceola County Health Dept; D Ginzl, MPH, D Walsh, K Sherin, MD, Orange County Health Dept; J Middaugh, MD, R Hammond, PhD, D Bodager, MPA, Bur of Community Environmental Health, Florida Dept of Health. K Komatsu, MPH, J Weiss, PhD, Arizona Dept of Health Services. N Pascoe, Texas Dept of State Health Svcs. F Marciano-Cabral, PhD, Virginia Commonwealth Univ. E Villegas, PhD, National Exposure Research Laboratory, US Environmental Protection Agency. G Visvesvara, PhD, J Yoder, MPH, $B$ Eddy, L Capewell, VMD, R Sriram, K Bandyopadhyay, PhD, Y Qvarnstrom, PhD, A DaSilva PhD, S Johnston, MS, L Xiao, PhD, V Hill, PhD, S Roy, MD, MJ Beach, PhD, Div of Parasitic Diseases, CDC.

\section{Editorial Note:}

Preliminary results of the review of PAM cases in the United States during 1937--2007 by the CDC/CSTE Naegleria Workgroup indicates that PAM is a rare disease that primarily affects young male users of warm recreational freshwaters, during summer months, in southern tier states. Although no estimate is available for the number of persons exposed to warm recreational freshwaters, given the increase in the U.S. population and the likelihood that more persons have been exposed over time, incidence of PAM does not appear to be increasing. Nonetheless, reports of PAM fatalities often prompt heightened public concern about the disease, and state and local health departments face challenges in assessing the risk from PAM and communicating that risk to the public.

In addition to conducting the review of PAM cases, objectives of the Naegleria Workgroup are to 1) update PAM risk-communication messages for health-care providers and the public, 2) propose making PAM a nationally notifiable disease, 3) develop a more extensive case-reporting form, and 4) review the role of environmental testing for $N$. fowleri. Although the workgroup continues to address these issues, this report contains its current findings and recommendations. 
Because PAM is a rare disease, it does not generate a high index of suspicion among health-care providers. Symptoms of $N$. fowleri infection (See box, below) are clinically similar to those for bacterial or viral meningitis, further lowering the index of suspicion for PAM and initiation of appropriate diagnostic testing $(1,2,4)$. Making PAM a nationally notifiable condition might improve case detection through increased awareness, reporting, and information about cases. Such information might enable earlier detection of infections, provide insight into the human or environmental determinants of infection, and allow improved assessment of treatment effectiveness.

In the United States, $N$. fowleri is commonly found in warm freshwater environments in southern tier states (5--7). The common finding of these amebae in the environment makes elimination from natural waters impractical. Because the location and number of amebae in the water can vary over time, environmental sampling, testing, and posting of warning signs are unlikely to be effective in preventing infections. In addition, warning signs posted on selected lakes might create a misconception that those bodies of water not posted with warnings are free from $N$. fowleri. Recreational water users should always assume a low level of risk is associated with entering all warm freshwaters in southern tier states.

The extremely low incidence of PAM makes epidemiologic study difficult; why certain persons become infected with the amebae while millions of others exposed to warm recreational freshwaters do not is unknown. Although attempts have been made to determine what concentration of $N$. fowleri in the environment poses an unacceptable risk, how a standard might be set to protect human health and how regulators might measure and enforce such a standard is unclear $(8)$.

Because a low level of risk from PAM likely exists for all users of warm freshwaters during summer to early fall, public health agencies should broadly disseminate evidence-based information on PAM in their recommendations for healthy swimming (See box, below). The only certain way to prevent $N$. fowleri infection is to refrain from water-related activities. However, although supporting data are absent, risk for infection might be reduced by measures that minimize water entering the nose when using warm freshwater lakes or rivers in southern tier states. Additional information on $N$. fowleri infection is available at http://www.cdc.gov/ncidod/dpd/parasites/naegleria.

\section{References}

1. Visvesvara GS, Moura H, Schuster FL. Pathogenic and opportunistic free-living amoebae: Acanthamoeba spp., Balamuthia mandrillaris, Naegleria fowleri, and Sappinia diploidea. FEMS Immunol Med Microbiol 2007;50:1--26.

2. Marciano-Cabral F, Cabral GA. The immune response to Naegleria fowleri amebae and pathogenesis of infection. FEMS Immunol Med Microbiol 2007;51:243--59.

3. Seidel JS, Harmatz P, Visvesvara GS, Cohen A, Edwards J, Turner J. Successful treatment of primary amebic meningoencephalitis. N Eng J Med 1982;306:346--8.

4. Barnett ND, Kaplan AM, Hopkin RJ, Saubolle MA, Rudinsky MF. Primary amoebic meningoencephalitis with Naegleria fowleri: clinical review. Pediatr Neurol 1996;15:230--4. 
5. Wellings FM, Amuso PT, Chang SL, Lewis AL. Isolation and identification of pathogenic Naegleria from Florida lakes. Appl Environ Microbiol 1977;34:661--7.

6. John DT, Howard MJ. Seasonal distribution of pathogenic free-living amebae in Oklahoma waters. Parasitol Res 1995;81:193--201.

7. Ettinger MR, Webb SR, Harris SA, McIninch, SP, Garman GC, Brown BL. Distribution of free-living amoebae in James River, Virginia, USA. Parasitol Res 2003;89:6--15.

8. Cabanes P-A, Wallet F, Pringuez E, Pernin P. Assessing the risk of primary amoebic meningoencephalitis from swimming in the presence of environmental Naegleria fowleri. Appl Environ Microbiol 2001;67:2927--31.

\section{Figure}

FIGURE, Number' of identified cases of primary amebic meningoencephalitis (PAM) - United States, 1937-2007

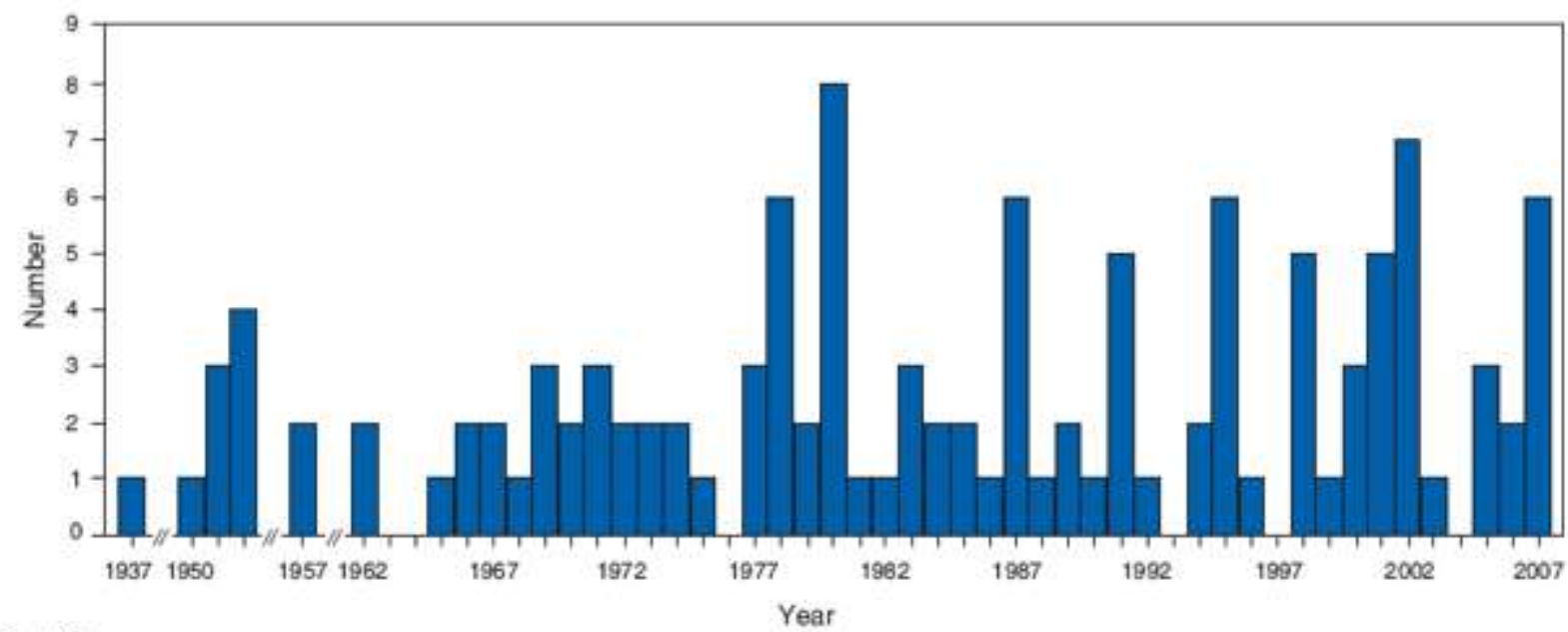

$\cdot N=121$

SOURCES: 1) the Waterborne Disease and Outbreak Surveillance System (collaboratively maintained by CDC, the U.S. Environmental Protection Apency, and the Council of State and Territorial Epidemiologists), which has tracked PAM cases since 1989; 2) the compressed mortality file of the National Vital Statistics System for cases reported during 1979-2007; 3) medical literature review of reported PAM cases, including those identified by retrospective examination of autopsy records; 4) searches of media reports since 1990, and 5) CDC laboratory test results. Results were veritied with public health officials from the state of diagnosis, and method of diagnosis was reviewed by the CDC parasitic disease laboratory. Cases were included if laboratory-confirmed detection of $N$. fowleri organisms or nuclec acid was reported in CSF, biopsy, or tissue specimens. 
General information

- Nacgleria fowleri, the thermophilic, free-living ameba that casues PAM, is common worldwide in warm freshwater bodies, including lakes, ponds, rivers, and hot springs; $N$. fowleri also can be found in improperly cleaned, maintained, or disinfected swimming pools.

- Sampling of warm water lakes in southern tier U.S. states indicates that $N$. fowleri is commonly present in most lakes during the summer.

- Because the location and number of amebae in the water can vary over time, posting warning signs is unlikely to be an effective way to prevent infections, and such signs might create a misconception that bodies of water without signs are $N$. fowleri-free.

- Information regarding the risks associated with $N$. fowleri infection should be disseminated rourinely through public health messages discussing general issues of water safety and risk.

- The $N$. fouleri CDC data collection survey instrument is available at http://www.cde.gov/ncidod/dpd/parasites/ naegleria.

\section{Clinical features of PAM}

- Signs and symptoms are similar to those of bacterial or viral meningiris and include headache, fever, stiff neck, anorexia, vomiting, altered mental status, seizure, and coma.

- Death typically occurs in 3-7 days.

- Autopsy findings show acute hemorrhagic necrosis of olfactory bulbs and cerebral cortex.

\section{Laboratory diagnosis}

- Visualization of actively moving $N$. fowleri trophozoites in a wet-mount preparation of freshly centrifuged cererbrospinal fluid (CSF) sediment (not previously refrigerated or frozen), or
- Visualization of $N$. fowleri trophozoites in a smear of centrifuged CSF sediment stained with Giemsa-Wright or modified trichrome stains, or

- Visualization of $N$. fowleri trophozoites by indirect fluorescent antibody in slide sections of either hematoxylincosin (H\&E)-stained unfixed/frozen brain tissue or $\mathrm{H} \& \mathrm{E}$-stained fixed brain tissue, or

- Demonstration of $N$. fowleri DNA by polymerase chain reaction from CSF or unfixed brain tissue samples.

\section{Recommended treatment}

- Recommended therapies include intravenous and intrathecal amphotericin B. Other drugs used include azithromycin, rifampin, and azole drugs.

- Intensive supportive care is required.

\section{Risk reduction measures}

- The only certain way to prevent $N$. fowleri infections is to refrain from water-related activities. However, some measures that might reduce risk by limiting the chance of contaminated water going up the nose include:

- Avoid water-rehated activities in bodies of warm freshwater, hot springs, and thermally polluted water such as water around power plants.

- Avoid water-related activities in warm fresh water during periods of high water temperature and low water volume.

- Hold the nose shut or use nose clips during activities in warm fresh water such as lakes, rivers. or hot springs.

- Avoid digging in or stirring up sediment during waterrelated activities in shallow, warm freshwater areas.

Use of trade names and commercial sources is for identification only and does not imply endorsement by the U.S. Department of Health and Human Services.

References to non-CDC sites on the Internet are provided as a service to $M M W R$ readers and do not constitute or imply endorsement of these organizations or their programs by CDC or the U.S. Department of Health and Human Services. CDC is not responsible for the content of pages found at these sites. URL addresses listed in MMWR were current as of the date of publication.

All MMWR HTML versions of articles are electronic conversions from typeset documents. This conversion might result in character translation or format errors in the HTML version. Users are referred to the electronic PDF version (http://www.cdc.gov/mmwr) and/or the original $M M W R$ paper copy for printable versions of official text, figures, and tables. An original paper copy of this issue can be obtained from the Superintendent of Documents, U.S. Government Printing Office (GPO), Washington, DC 20402-9371; telephone: (202) 512-1800. Contact GPO for current prices.

\section{**Questions or messages regarding errors in formatting should be addressed to} mmwrq@cdc.gov. 